\title{
An Investigation of Temperature and Wind Impact on ACSR Transmission Line Sag and Tension
}

\author{
Muhammad Zulqarnain Abbasi \\ Electrical Engineering Department \\ IQRA National University \\ Peshawar, Pakistan
}

\author{
Sidra Farooqi \\ Electrical Engineering Department \\ IQRA National University \\ Peshawar,Pakistan
}

\author{
Babar Noor \\ Electrical Engineering Department \\ IQRA National University \\ Peshawar, Pakistan
}

\author{
Muhammad Aamir Aman \\ Electrical Engineering Department \\ IQRA National University \\ Peshawar, Pakistan
}

\author{
Fazal Wahab Karam \\ Electrical Engineering Department \\ COMSATS University Abbottabad \\ Pakistan
}

\begin{abstract}
Power transmission is mainly based on overhead transmission lines with conductors being supported by transmission towers. Transmission lines are subjected to environmental stress (temperature changes, winds, snow etc), have an impact on the surrounding areas (visual pollution, building restrictions) and experience heavy losses due to resistive, magnetic and capacitive effects. Thus, proper modeling and installation of these conductors are necessary. The conductors are generally installed in a catenary shape to minimize the capacitive effects and to balance the tension. This paper presents an investigation on the sag and tension behavior under different temperature and wind of ACSR (Aluminum Conductor-Steel Reinforced) lines. Four different cases of temperature and wind are tested to calculate sag and tension. Simulation setup is done in ETAP (electrical transient and analysis program). Results are recorded and discussed.
\end{abstract}

Keywords-ACSR; overhead; line; transmission; conductors; span; sag; temperature; variation

\section{INTRODUCTION}

Overhead transmission lines are used to carry electrical power over long distances [1]. The performance of these transmission lines depends on their well-engineered modeling which is one of the major issues issue during the design stage. [2]. If the support structures are at the same height (which is rarely the case, however it provides a simplified base to study other parameters), then the sag is the height difference between the conductor's lowest point and the height of the supporting points [3]. During the design (and construction) phase many parameters are to be considered. Among them, the calculated tension, the safety distances (clearances), the location of rural areas etc. Thus, mechanical modeling as well as geospatial data are usually employed [4]. The design stage results to certain routing, placement of towers, tower types, conductor sag and tension throughout the route [5]. Different types of conductors are used for the transmission of electrical energy e.g. AAC (All Aluminum Conductor), AAAC (All Aluminum Alloy Conductor), HTLS (High Temperature Low Sag), ACSS (Aluminum Conductor, Steel-Supported), ACSR (Aluminum
Conductor-Steel Reinforced) with ACSR being probably the most usual choice for transmission lines. ACSR has a galvanized steel core that carries the mechanical load and outer strands made of high purity aluminum that carry the current [6]. To meet changing necessities, ACSR is accessible in an extensive variety of steel substance - from $7 \%$ by weight for the $36 / 1$ stranding to $40 \%$ for the $30 / 7$ stranding. Early ACSR outlines, for example, 6/1, 30/7, 30/19, 54/19 and 54/7 stranding, included high steel content, $26 \%$ to $40 \%$, with accentuation on quality because of the fear of vibration fatigue. Today, for bigger sizes, the most utilized standings are 18/1, $45 / 7,72 / 7$, and $84 / 19$, involving a scope of steel substance from $11 \%$ to $18 \%$. For the modestly higher quality $54 / 19,54 / 7$, and $26 / 7$ standings the steel substance is $26 \%, 26 \%$ and $31 \%$, respectively. The high-quality ACSR 8/1, 12/7 and 16/19 standings are commonly utilized in special cases (e.g. intersections) [6]. Overhead transmission lines are subjected to a variety of environmental stresses during their lifetime. Sag or dip is considered in order to keep tension as low as possible. Sag is conversely corresponding to the transmission line tension [6]. As the ground level varies in hilly areas so, the sag also does not remain constant [7].Wind is a main common factor to most transmission lines and thus wind impact is often investigated (e.g. [6]). The minimum distance of a conductor from the ground is set by each county (and usually it also depends on the installations found-or to be constructed- under the line) but some usual distances are shown in Table I.

TABLE I. VOLTAGE WITH GROUND CLEARANCE LEVEL

\begin{tabular}{|c|c|}
\hline Voltage Level & Clearance to Ground \\
\hline Less than $66 \mathrm{kV}$ & 20 feet \\
\hline $66 \mathrm{kv}$ to $110 \mathrm{kv}$ & 21 feet \\
\hline $110 \mathrm{kv}$ to $165 \mathrm{kv}$ & 22 feet \\
\hline Greater than $165 \mathrm{kv}$ & 23 feet \\
\hline
\end{tabular}

\section{MECHANICAL DESIGN OF A TRANSMISSION LINE}

The sag of a transmission line depends on the following factors: the conductor's weight, the span (distance between the 
supports), the transmission line tension, the weather conditions and the temperature.

\section{A. The Catenary Curve}

When a perfectly flexible wire of uniform weight is hung between two horizontal supports [8] it will form a catenary with $\mathrm{L}$ be the span distance, $\mathrm{W}$ the weight per unit length of the conductor, $\mathrm{t}_{0}$ the tension at the dip of the conductor in $\mathrm{kg}$ i.e. $\mathrm{t}_{0}=\mathrm{WC}, \varnothing$ the angle between the tension and the horizontal axis. Then if we consider a travelling point $\mathrm{p}(\mathrm{A}, \mathrm{B})$ on the transmission line up to the point $\mathrm{O}$ (sag point), then this length may be termed as $\mathrm{S}$. Three forces are acting on $\mathrm{S}$ : the horizontal tension $\mathrm{t}_{0}=\mathrm{WC}$, the weight i.e. WS and the tension $\mathrm{t}$.

So:

$$
\begin{aligned}
& \mathrm{S}=\mathrm{C} \sin h \frac{A}{C} \\
& \mathrm{~S}=\mathrm{C}\left(\frac{A}{C}+\frac{A^{3}}{3 ! C^{3}}+\frac{A^{5}}{5 ! C^{5}}+\cdots\right) \\
& \mathrm{S}=\mathrm{A}+\frac{A^{3}}{6 C^{2}}
\end{aligned}
$$

$\mathrm{Y}=$ Point $\mathrm{p}(\mathrm{A}, \mathrm{B})$ measured above the origin vertically.

$$
\begin{aligned}
& \mathrm{Y}=\mathrm{C} \cos h \frac{A}{C} \\
& \mathrm{Y}=\mathrm{C}\left(1+\frac{A^{2}}{2 ! C^{2}}+\frac{A^{4}}{2 ! C^{2}}+\cdots\right) \\
& \mathrm{Y}=\mathrm{C}+\frac{A^{2}}{2 C}
\end{aligned}
$$

\section{B. Sag Calculations}

By using (6) we get:

$$
Y-C=\frac{\mathrm{A}^{2}}{2 \mathrm{C}}=D_{x}
$$

Sag is maximum when $\mathrm{A}=\frac{L}{2}$

$$
\begin{gathered}
D_{\max }=\frac{\mathrm{L}^{2}}{8 \mathrm{C}} \\
D=\frac{\mathrm{W} \mathrm{L}^{2}}{8 \mathrm{t}}
\end{gathered}
$$

For the whole conductor $l$ sag is

$$
S=A+\frac{\mathrm{A}^{3}}{6 \mathrm{C}^{2}}
$$

Substituting $A=L / 2$ to get the length of the conductor between the point $\mathrm{o}$ and the support end $\mathrm{a}$ or $\mathrm{b}$.

$\frac{1}{2}=\frac{\mathrm{L}}{2}+\frac{\mathrm{L}^{3}}{48 \mathrm{C}^{2}}$ and $l=L+\frac{L^{3}}{24 C^{2}}$ for the level supports.

\section{Wind Effect on Line Sag}

On transmission lines, the wind is usually assumed to be acting horizontally and is measured in $\left(\mathrm{kg} / \mathrm{m}^{2}\right)$. If we consider a conductor with length $1 \mathrm{~m}$ and diameter $\mathrm{D}$ and wind being applied from a point $\mathrm{P}$ horizontally [8], then the wind effect is calculated with ice and without ice effect as:

$$
\begin{aligned}
& W_{W}=P . D .1 \text { without ice effect } \\
& W_{W}=P .(D+2 t) .1 \text { with ice effect }
\end{aligned}
$$

where $\mathrm{W}_{\mathrm{W}}=$ Weight of the conductor in $\mathrm{Kg} / \mathrm{m}^{2}$

With the effect of wind the sag makes an angle $\theta$ vertically which is termed as vertical sag and is equal to

$$
D_{\text {Vertical }}=D \cos \theta
$$

\section{SYSTEM IMPLEMENTATION}

\section{A. Modeling and Load Flow Analysis}

The ETAP 12.6 [9] software is used for the estimation of sag and tension of ACSR transmission line. ETAP transmission and distribution line sag and tension module is an important tool to perform sag and tension calculation for transmission and distribution lines to ensure adequate operating condition for the lines [10]. For simulation setup, the model selected is a $500 \mathrm{kV}$ transmission line between Tarbela and Sheikh Mohammadi grid station (Pakistan). The model and its load flow analysis [11] is shown in Figure 1. The tower heights are set to $16 \mathrm{~m}$. The selected conductor is ACSR and the configuration is horizontal. Load flow analysis is performed in ETAP based on the Newton Raphson Method 10 (Figure 1). The losses are then analyzed using the sag and tension library [12]. Figure 2 shows the different parameters used.

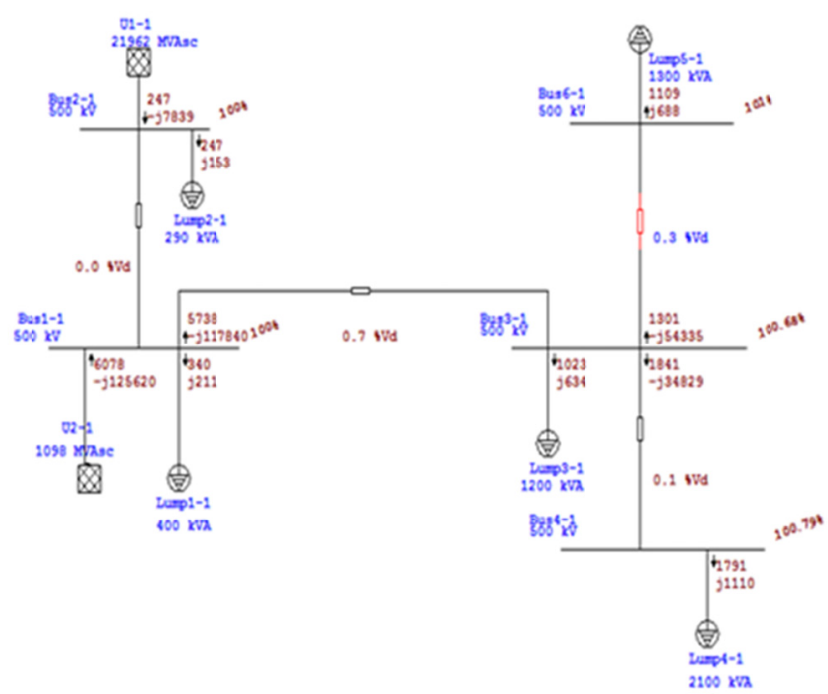

Fig. 1. The transmission line model and its load flow analysis.

\section{RESULTS AND DISCUSSION}

Four different cases of temperature and wind are considered on ACSR conductors with level supports.

\section{A. Case 1}

Five different span lengths are analyzed under minimum temperature i.e. $5{ }^{\circ} \mathrm{C}$ with wind speed $25 \mathrm{~N} / \mathrm{m}^{2}$ using ACSR and the corresponding values of tension and sag are shown (Table II).

\section{B. Case 2}

In Case 2, the temperature is the same with Case 1 but the wind speed is higher $\left(50 \mathrm{~N} / \mathrm{m}^{2}\right)$. Due to the wind effect, the conductor tension changes while sag is hardly affected. Results are shown in Table III.

\section{Case 3}

In case 3 , the maximum operating temperature $\left(50^{\circ} \mathrm{C}\right)$ is considered with a wind speed of $25 \mathrm{~N} / \mathrm{m}^{2}$. As shown, the higher temperature results to larger sag (Table IV). 

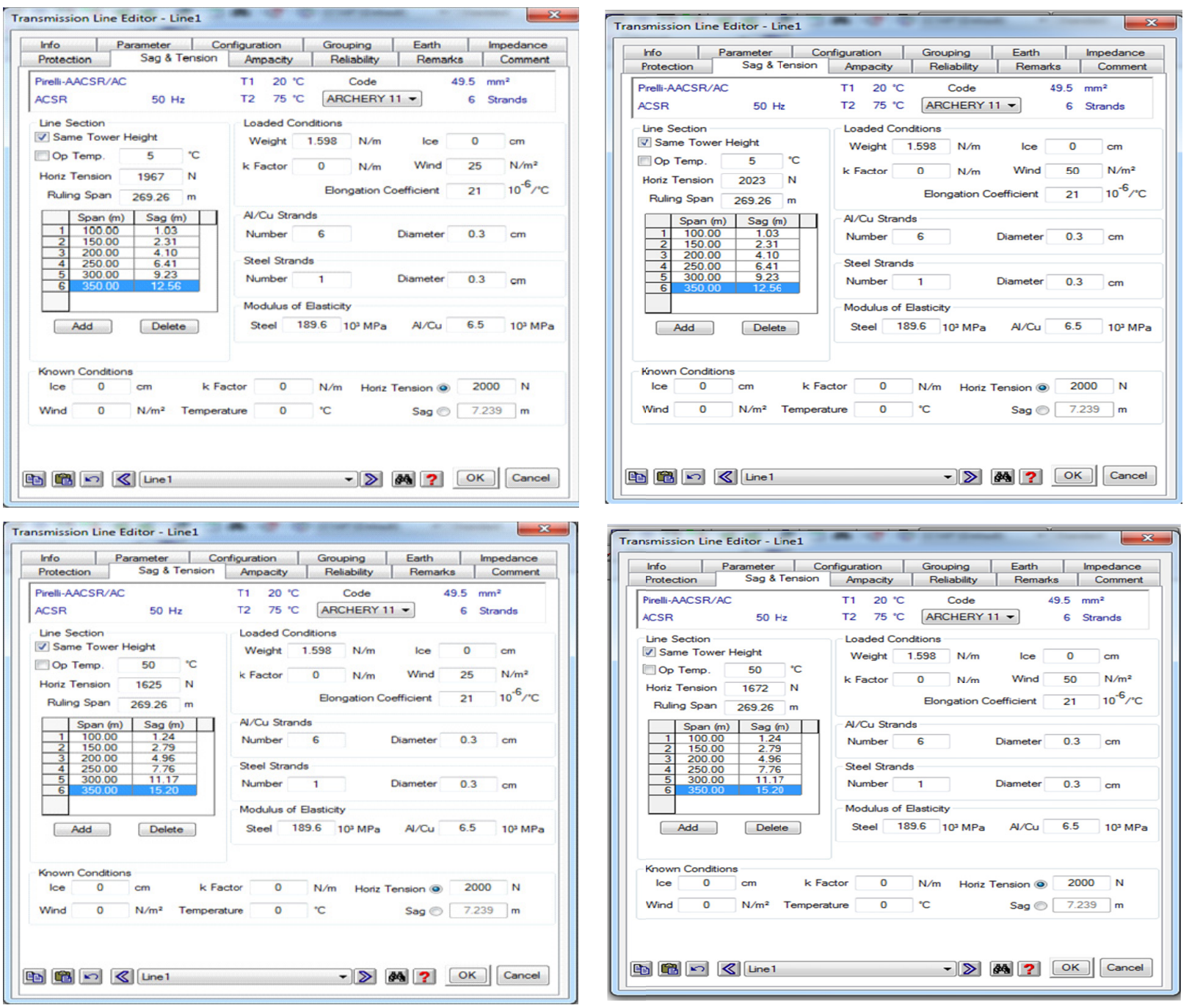

Fig. 2. ETAP editors for different temperature and wind effects on ACSR conductor for finding sag of different spans

TABLE II. OPERATING TEMPERATURE $5^{\circ} \mathrm{C}$

\begin{tabular}{|c|c|c|c|}
\hline $\begin{array}{c}\text { Span } \\
(\mathbf{m})\end{array}$ & $\begin{array}{c}\text { Wind speed } \\
\left(\mathbf{N} / \mathbf{m}^{\mathbf{2}}\right)\end{array}$ & Sag & Tension \\
\hline 100 & 25 & 1.03 & 1967 \\
\hline 150 & 25 & 2.31 & 1951 \\
\hline 200 & 25 & 4.1 & 1927 \\
\hline 250 & 25 & 6.41 & 1889 \\
\hline 300 & 25 & 9.23 & 1825 \\
\hline
\end{tabular}

TABLE III. OPERATING TEMPERATURE $5{ }^{\circ} \mathrm{C}$

\begin{tabular}{|c|c|c|c|}
\hline $\begin{array}{c}\text { Span } \\
(\mathbf{m})\end{array}$ & $\begin{array}{c}\text { Wind speed } \\
\left(\mathbf{N} / \mathbf{m}^{\mathbf{2}}\right)\end{array}$ & Sag & Tension \\
\hline 100 & 50 & 1.03 & 2023 \\
\hline 150 & 50 & 2.31 & 2007 \\
\hline 200 & 50 & 4.1 & 1982 \\
\hline 250 & 50 & 6.41 & 1943 \\
\hline 300 & 50 & 9.23 & 1877 \\
\hline
\end{tabular}

TABLE IV . OPERATING TEMPERATURE $50^{\circ} \mathrm{C}$

\begin{tabular}{|c|c|c|c|}
\hline $\begin{array}{c}\text { Span } \\
(\mathbf{m})\end{array}$ & $\begin{array}{c}\text { Wind speed } \\
\left(\mathbf{N} / \mathbf{m}^{\mathbf{2}}\right)\end{array}$ & Sag & Tension \\
\hline 100 & 25 & 1.24 & 1625 \\
\hline 150 & 25 & 2.79 & 1541 \\
\hline 200 & 25 & 4.96 & 1433 \\
\hline 250 & 25 & 7.76 & 1294 \\
\hline 300 & 25 & 11.17 & 1119 \\
\hline
\end{tabular}

TABLE V. OPERATING TEMPERATURE $50^{\circ} \mathrm{C}$

\begin{tabular}{|c|c|c|c|}
\hline $\begin{array}{c}\text { Span } \\
(\mathbf{m})\end{array}$ & $\begin{array}{c}\text { Wind speed } \\
\left(\mathbf{N} / \mathbf{m}^{\mathbf{2}}\right)\end{array}$ & Sag & Tension \\
\hline 100 & 50 & 1.24 & 1672 \\
\hline 150 & 50 & 2.79 & 1585 \\
\hline 200 & 50 & 4.96 & 1474 \\
\hline 250 & 50 & 7.76 & 1317 \\
\hline 300 & 50 & 11.17 & 1152 \\
\hline
\end{tabular}




\section{Case 4}

In Case 4, temperature is set to $50{ }^{\circ} \mathrm{C}$ but the wind speed is set to $50 \mathrm{~N} / \mathrm{m}^{2}$. The conductor tension increases while sag is hardly affected (Table V).

\section{CONCLUSION}

A significant factor in overhead transmission line design is sag and tension calculation which is performed considering the potential environmental stresses that the transmission line is expected to suffer throughout its life time. The most common environmental stress factors are wind and temperature. Their impact is investigated in this paper, considering a part of an actual transmission line in Pakistan modeled in ETAP. Four different cases are considered and results show that an increase in temperature has a direct impact on sag whereas an increase in wind has a direct impact on tension.

\section{REFERENCES}

[1] J. Quintana, V. Garza, C. Zamudio, "Sag-tension calculation program for power substations", 42nd Annual Conference of the IEEE Industrial Electronics Society, IECON 2016, Florence, Italy, pp. 3889-3893, IEEE, 2016

[2] M. Keshavarzian, C. H. Priebe, "Sag and tension calculations for overhead transmission lines at high temperatures-modified ruling span method", IEEE Transactions on Power Delivery, Vol. 15, No. 2, pp. 777-783, 2000

[3] V. K. Mehta, R. Mehta, Principles of Power Systems, S. Chand, New Delhi, India, 2011

[4] D. Pylarinos, I. Pellas, "Incorporating Open/Free GIS and GPS Software in Power Transmission Line Routine Work: The Case of Crete and Rhodes", Engineering, Technology \& Applied Science Research, Vol. 7, No. 1, pp. 1316-1322, 2017

[5] M. T. Bedialauneta, I. Albizu, E. Fernandez, A. J. Mazon, S. de Arriba, "Monitoring the tension and the temperature in an overhead line", 16th IEEE Mediterranean Electrotechnical Conference (MELECON), Yasmine Hammamet, Tunisia, pp. 245-248, IEEE, 2012

[6] F. I. Oluwajobi, O. S. Ale, A. Ariyanninuola, "Effect of sag on transmission line", Journal of Emerging Trends in Engineering and Applied Sciences, Vol. 3, No. 4, pp. 627-630, 2012

[7] Southwire Company, Overhead conductor manual, Southwire Company, Carrollton, Georgia, USA, 2007

[8] A. K. Akhani, Mechanical design of overhead transmission lines, available at: http://top10electrical.blogspot.gr/2014/12/mechanicaldesign-of-overhead.html, 2014

[9] ETAP, "Line Sag \& Tension Analysis", available at: etap.com/product/line-sag-tension

[10] C. J. Soni, P. R. Gandhi, S. M. Takalkar, "Design and analysis of $11 \mathrm{kv}$ distribution system using ETAP software", 2015 International Conference on Computation of Power, Energy Information and Commuincation, Chennai, India, pp. 0451-0456, IEEE, 2015

[11] M. Aien, R. Ramezani, S. Mohsen Ghavami, "Probabilistic load flow considering wind generation uncertainty", Engineering, Technology \& Applied Science Research, Vol. 1, No. 5, pp. 126-132, 2011

[12] M. A. Aman, S. Ahmad, A. Asar, B. Noor, "Analyzing the diverse impacts of conventional distributed energy resources on distribution system", International Journal of Advanced Computer Science and Applications, Vol. 8, No. 10, pp. 390-396, 2017 